\title{
LÍNGUA, LITERATURA E TEORIA EM GEORGES PEREC
}

Jacques Fux e Henrique Lee

\section{RESUMO}

O presente artigo aborda algumas relaçóes possíveis entre espaço e literatura na obra do escritor francês Georges Perec, da qual se toma como ponto de referência primordial o livro Espèces d'espaces, publicado em 1974. A partir desta obra - e de uma observaçáo em sua contracapa, na versão em inglês, na qual afirma que esta se trata de uma obra náo ficcional - procura-se refletir a respeito dos deslocamentos que a estrutura narrativa do texto propicia sobre o estatuto do ficcional.

PALAVRAS-CHAVE: espaço; ficção; Georges Perec; classificação.

\section{Motivação}

pergunta teórica que move este trabalho surgiu de uma breve registro que se encontra na contracapa de uma edição inglesa para o livro Espèces d'espaces ${ }^{l}$, do francês Georges Perec. O tradutor e crítico inglês John Sturrock apresenta o livro como uma "[...] generosa seleção da obra não ficcional de Perec [...]”2. O que há de curioso nessa menção é o fato de ela afirmar - ou, se preferirmos, sugerir - um estatuto não ficcional para o livro, bem como para outros trabalhos do autor.

PEREC, Georges. Espèces d'espaces. Paris: Galilée, 2000.

2 STURROCK, John. Contracapa. In: PEREC, Georges. Species of Space and other pieces. London: Penguim Twentieth Century Classics, 1997. 
A forma proposta por John Sturrock para classificar aqueles escritos como não ficcionais causa certa surpresa e parece mesmo confirmar a hipótese de Wolfgang Iser segundo a qual o ficcional seria definido pelo saber tácito como algo cujo atributo de realidade se encontra ausente ${ }^{3}$. No caso do livro de Perec, a colocação de Sturrock reafirma a inversa complementar: ao olhar deste saber tácito, Espèces d'espaces parece ser uma obra carente de atributos de ficcionalidade.

Porém é justamente nesse livro que Perec questiona os limites e as questôes de classificação, ficção e também de memória. Qualquer tentativa de nomear ou agrupar elementos literários como ficcionais ou não ficcionais é inútil, como afirma o autor. Neste artigo, portanto, tentaremos problematizar essas questóes na obra do escritor francês.

O espaço e as classificaçóes de perec

Perec, em Espèces d'espaces, escreve:

O problema não é inventar o espaço, menos ainda reinventálo (muita gente bem intencionada está aí hoje para pensar o nosso ambiente), mas de interrogá-lo, ou mais ainda, de lê-lo, pois isso que chamamos cotidianidade não é evidência, mas opacidade: uma forma de cegueira, uma forma de anestesia ${ }^{4}$.

Assim, o autor propóe, através de um exercício que toma por objeto o espaço, uma interrogação e uma leitura de tudo aquilo que nos é dado como evidência e obviedade. Perec questiona, consequentemente, os estratos que sustentam a oposição binária entre discursos ficcionais e referenciais, e entre narração e descrição. Dessa forma, o livro de Perec, assim como parte significativa da literatura contemporânea, encontra-se em um regime de inclassificabilidade. Certamente, o que há de inclassificável nesses textos não é um caráter intrínseco aos mesmos ou algo exterior aos modos de classificação através da

3 ISER, Wolfgang. O fictício e o imaginário. Rio de Janeiro: Editora UERJ, 1996.

4 Le problème n'est pas d'inventer l'espace, encore moins de le ré-inventer (trop de gens bien intentionnés sont là aujourd'hui pour penser notre environnement...), mais de l'interroger ou, plus encore, de le lire; car ce que nous appelons quotidienneté n'est pas évidence, mais opacité: une forme de cécité, une manière d'anesthésie PEREC, Georges. Espèces d'espaces. Paris: Galilée, 2000. Encarte. As traduções do texto de Perec são nossas. 
qual certa tradição da teoria literária demarcou e classificou o espaço artístico da literatura, mas a interrogação sobre o estatuto ficcional dos elementos artísticos e literários que conduz a uma discussão de sua própria classificação enquanto tal. Assim, problematiza Perec:

Se eu tento definir o que procurei fazer desde que comecei a escrever, a primeira ideia que me vem é que jamais escrevi dois livros iguais. [...] Minha ambição de escrever seria a de percorrer toda a literatura do meu tempo sem jamais ter o sentimento de voltar nos meus passos ou de caminhar novamente pelos meus próprios traços e de escrever tudo o que é possível a um homem de hoje escrever: livros grandes e curtos, romances, poemas, dramas, livretos de ópera, romances policiais, romances de aventura, romances de ficção científica, folhetos, livros para crianças 5 .

Além disso, Perec tem outra ambição como escritor: a de criar espaços em branco e escrever sobre as margens: "J'écris: j'habite ma feuille de papier, je l'investis, je la parcours. Je suscite des blancs, des espaces (sauts dans le sens: discontinuités, passages, transitions) " 6 . O autor propóe novos caminhos, novas possibilidades e um debate com outros pensadores, como observa Cláudia Amigo Pino:

Ou seja, a página não é um suporte, não é uma folha de papel, também não é uma das caras dessa folha: ela é o ato de habitar a folha, o percurso do escritor, e esse percurso consiste em "criar brancos". Essa visão coincide com, mas também contradiz a visão dos profissionais do livro. Por um lado, eles usam a palavra página para designar a superfície impressa de uma folha, o que nos faz pensar nessa noção de percurso do escritor. Mas, segundo essa definição, as margens não fazem parte da página, são as diferenças entre a folha e a página. Lembremos que Perec

5 PEREC apud BURGELIN, Claude. Georges Perec. Paris: Éditions Seuil, 1988, p. 11.

6 PEREC, Georges. Espèces d'espaces. Paris: Galilée, 2000, p. 23. 
afirma que o percurso do escritor consiste em criar espaços em branco, ou seja, em criar, também, margens. A definição de Perec remete ao mesmo problema da poética de Bachelard: ele também de alguma forma se refere a um espaço perdido. Ao colocar a produção de página como produção de brancos, ele está nos dizendo que a página cheia, que a página escrita, está perdida ${ }^{7}$.

Como, portanto, classificar esse livro de Perec como não ficcional se ele justamente propõe novas formas e possibilidades ficcionais? Questionando e respondendo os seus próprios meios classificatórios, Perec, em seu livro Pensar/ Classificar, argumenta sobre os critérios que poderiam nortear a divisão e a classificação de sua obra literária:

[...] los libros que escribí se asocian con cuatro campos diferentes, cuatro modos de interrogación que quizá formulan, a fin de cuentas, la misma pregunta, pero la formulan según perspectivas particulares que en cada ocasión representan para mí otro tipo de labor literaria. La primera de estas interrogaciones se puede calificar como "sociológica": cómo observar lo cotidiano; ella dio origen a textos como Les Choses, Espèces d'espaces, Tentative de description de quelques lieux parisens, [...]; la segunda es de orden autobiográfico: W ou Le souvenir d'enfance, La boutique obscure, Je me souviens, Lieux ou j'ai dormi, etcétera; la tercera, lúdica, remite a mi gusto por los constreñimientos, las proezas, las "gamas", por todos los trabajos para los cuales las investigaciones del OuLiPo me dieron la idea y los medios: palíndromos, liprogramas, pangramas, anagramas, isogramas, acrósticos, palabras cruzadas, etcétera; la cuarta, por último, concierne a lo novelesco, al gusto por las historias y peripecias, al deseo de escribir libros que se devoren de bruces en la cama;

7 PINO, Cláudia Amigo. "O espaço de Modo de Usar: Georges Perec" Lettres françaises, $\mathrm{n}$. 7, 2009. p. 123-134. http://200.145.78.103/lettres/article/view/2020/1649, Acessado em março 03/2012, p. 125. 
La vie mode d'emploi es el ejemplo típico de ello. Esta división es algo arbitraria y podría ser mucho más matizada: casi ninguno de mis libros escapa del todo a cierta marca autobiográfica [...]; casi ninguno, por otra parte, deja de recurrir a tal o cual constreñimiento o estructura "oulipiana"

Ao esgotar as possibilidades autobiográficas, estruturais, restritivas, cotidianas e lúdicas, Perec está discutindo a própria possibilidade ficcional que Sturrock classificou equivocadamente como não ficcional. Assim, podemos ler a próxima citação de Perec como uma tentativa de exaurir as criaçóes e os substratos ficcionais:

Existem poucos acontecimentos que não deixem ao menos um traço escrito. Quase tudo, em um momento ou outro, passa por uma folha de papel, uma página de caderno, uma folha de agenda e não importa em que suporte improvisado (um bilhete de metrô, a margem de um jornal, um maço de cigarros, o dorso de um envelope, etc.) sobre o qual vem se inscrever, em uma velocidade variável e segundo técnicas diferentes de acordo com o lugar, a hora ou o humor, um ou outro dos diversos elementos que compóe o ordinário da vida, no que me diz respeito (mas sem dúvida sou um exemplo muito bem escolhido, já que uma de minhas atividades principais é precisamente escrever), de um endereço tomado em pleno voo, de um encontro anotado às pressas, no canhoto de um cheque, no envelope ou pacote, à redação laboriosa de uma carta administrativa, o preenchimento fastidioso de um formulário?.

8 PEREC, Georges. Pensar/Classificar. 2. ed. Barcelona: Gedisa, 2001, p. 11.

9 Il y a peu d'événements qui ne laissent au moins une trace écrite. Presque tout, à un moment ou à un autre, passe par une feuille de papier, une page de carnet, un feuillet d'agenda ou n'importe quel autre support de fortune (un ticket de métro, une marge de journal, un paquet de cigarettes, le dos d'une enveloppe, etc.) sur lequel vient s'inscrire, à une vitesse variable et selon des techniques différentes selon le lieu, l'heure ou l'humeur, l'un ou l'autre des divers éléments qui composent l'ordinaire de la vie cela va, en ce qui me concerne (mais sans doute suis-je un exemple trop bien choisi, puisque l'une de mes activités principales est précisément d'écrire), d'une adresse prise au vol, d'un rendez-vous noté à la hâte, du libellé 
Perec, através dessa citação e da sua obra, nos conduz, segundo Foucault:

a um pensamento sem espaço, a palavras e categorias sem tempo nem lugar, mas que, em essência, repousam sobre um espaço solene, todo sobrecarregado de figuras complexas, de caminhos emaranhados, de locais estranhos, de secretas passagens e imprevistas comunicaçóes; haveria assim, na outra extremidade da terra que habitamos, uma cultura voltada inteiramente à ordenação da extensão, mas que não distribuiria a proliferaçáo dos seres em nenhum dos espaços onde nos é possível nomear, falar, pensar ${ }^{10}$.

Ao estudar a utilizaçáo de diversas e novas ferramentas na contemporaneidade, Zygmunt Bauman ${ }^{11}$, em Modernidade líquida, relaciona essa quebra de fronteiras à noção de "fluidez", afirmando que os fluidos se movem com grande facilidade e estão, constantemente, prontos para mudança. Bauman faz uso de duas categorias distintas, "líquido" e "sólido", com intuito de diferenciar as principais características do mundo contemporâneo, recorrendo à "liquidez" como metáfora para compreender a natureza da nova fase. De acordo com a teoria de Bauman, que pode muito bem ser aplicada à obra de Perec, há uma fusão dos padrôes, das fronteiras e das molduras que estabeleciam as classes e garantiam a ordem, resultando em multiplicidade, misturas e hibridismos, abrindo espaço na utilização do diferente.

Corroborando essa ideia, Roland Barthes, em Fragmentos de um discurso amoroso, ${ }^{12}$ se vale da palavra grega atopos para designar o problema da classificação, apontando não só a sua instabilidade, mas também a resistência à descrição e definição, caracterizando o que é estranho, extraordinário, insólito e original. A nova questão nos remete à palavra "inclassificável”, aquilo que não pode ser inserido dentro de uma categoria ou classe, o que está em desor-

d'un chèque, d'une enveloppe ou d'un paquet, à la rédaction laborieuse d'une lettre administrative, du remplissage fastidieux d'un formulaire [...] PEREC, Georges. Espèces d'espaces. Paris: Galilée, 2000, p. 24.

10 FOUCAULT, Michel. As palavras e as coisas. São Paulo: Martins Fontes, 2007, p. XIV.

11 BAUMAN, Zygmunt. Modernidade Liquida. Rio de Janeiro: J. Zahar, 2001.

12 Barthes, R. Fragmentos de um discurso amoroso. São Paulo: ediçóes 70, 2001. 
dem, em confusão: o ornitorrinco de Umberto Eco. O hibridismo é digno de atenção e também, frequentemente, alvo de censura e de reprovação. A obra de Perec, repleta de listas e arquivos fragmentados, configura uma desordem híbrida dos códigos culturais e ficcionais, revelando seu caráter barthesiano atópico.

\section{Teorias da ficção}

Uma parte considerável das primeiras correntes teórico-críticas voltadas à literatura, entre elas o formalismo russo, dedicou-se à tentativa de delimitar o que seria o campo do literário ${ }^{13}$. Esses esforços, muitas vezes baseadas em aspectos imanentes ao texto (e transcendentes no que diz respeito aos contextos históricos e culturais), nos fornecem um bom exemplo de como a descrição teria sido, por vezes, tomada como o avesso daquilo que pertenceria ao campo literário. ${ }^{14}$

Iuri Lotman, teórico da escola do formalismo russo, em suas teorizaçóes sobre a estrutura do texto artístico, coloca ênfase na função modelizante do espaço e da representação espacial no texto artístico. O espaço seria, dentro desse modelo teórico, condição de possibilidade da ocorrência de um acontecimento no texto literário:

O acontecimento no texto é o deslocamento da personagem através da fronteira do campo semântico. [...] Mas na medida em que, ao lado de uma disposição semântica geral do texto, há lugar também para disposiçóes locais, de que cada um tem a sua fronteira conceptual, o acontecimento pode ser realizado como uma hierarquia de acontecimentos de planos mais particulares, como uma cadeia de acontecimentos, isto é, como uma trama ${ }^{15}$.

13 LIMA, Luiz Costa. A teoria da literatura em suas fontes. Rio de Janeiro: Civilização Brasileira, 2002, p. 19.

14 Para os fins da discussão levantada no escopo desse artigo estamos tomando por similares, ainda que conscientes da inexatidão de tal equivalência, o ficcional e o literário. No entanto, acreditamos que as saliências e contrastes entre os dois termos não implicarão prejuízo à análise proposta.

15 LOTMAN, Iuri. A estrutura do texto artístico. Lisboa: Estampa, 1978, p. 379. 
Na proposta de Lotman, o acontecimento - e, por consequência, a trama - são os dois operadores que caracterizam o texto literário. Faz-se necessário um movimento de transgressão das fronteiras dos campos semânticos dispostos no texto para ocasionar a emergência do acontecimento, e é a partir das cadeias de acontecimentos que se constitui uma trama. $\mathrm{O}$ autor vai recorrer a alguns modelos para exemplificar o que seria o texto sem trama, como o mapa e a lista telefônica, cujos espaços de distribuição dos objetos são regidos pela aleatoriedade classificatória: "Os textos sem trama têm um caráter nitidamente classificador, eles afirmam o mundo e sua disposição"16.

Ao acompanharmos a construção de Lotman, é possível perceber uma estreita associação entre os textos sem trama e os textos de vocação descritiva. Uma descrição "pura" seria, assim, aquela em que todos os elementos descritos encontrar-se-iam em um mesmo nível de privilégio do ponto de vista da representação, ou seja, numa situação em que não haveria perspectiva nem diferenciação entre figura e fundo - situação que excluiria necessariamente a ideia de trama, uma vez que esta apenas se constitui a partir da hierarquização dos acontecimentos.

Subjaz a essa perspectiva a ideia de que essas afirmaçóes de estado de mundo, essas descriçôes "puras" não possuem intencionalidade, no sentido de que não há o posicionamento de uma perspectiva, de um olhar (como se a aleatoriedade não pudesse ser pensada também enquanto uma perspectiva). Todavia, o que nos interessa destacar é o esforço empreendido por Lotman para definir estes elementos estruturais - o acontecimento e a trama - como operadores do texto literário.

Para tentarmos estabelecer uma compreensão um pouco mais clara da forma de composiçấo e funcionamento desses elementos estruturais, é interessante destacarmos os desdobramentos do exemplo do mapa. Um mapa, segundo Lotman, é um texto sem trama; mas, se a ele for acrescentado algum outro elemento, como uma seta ou uma marca, poderíamos então passar a falar da ocorrência de um acontecimento. Já haveria a estratificação dos campos que fazem emergir os elementos mínimos para o estabelecimento de uma trama: "o texto com trama constrói-se na base do texto sem trama enquanto negação deste" 17 .

${ }_{16}$ LOTMAN, Iuri. A estrutura do texto artístico. Lisboa: Estampa, 1978, p. 384.

17 LOTMAN, Iuri. A estrutura do texto artístico. Lisboa: Estampa, 1978, p. 386. 
Dessa maneira, se tomarmos os elementos estruturais propostos por Lotman como balizas de leitura para pensarmos a "ficcionalidade" ou a "literalidade” em Espèces de espaces, os resultados serão no mínimo surpreendentes. $\mathrm{O}$ que parece ser apenas a descrição da aleatoriedade absurda dos espaços, o que a princípio é um texto sem acontecimento e sem trama sofre uma sutil transformação ao longo do livro: o acúmulo de descriçôes forma séries heterogêneas, de modo que a própria heterogeneidade passa a funcionar como um acontecimento. Ou seja, através da saturaçáo da tentativa de empreender uma descrição exaustiva, que apenas afirme o mundo e sua disposição, uma "trama" se produz em Espèces d'espaces. Se "a trama é um elemento revolucionário relativamente à imagem do mundo" 18 , podemos concluir que no livro de Perec ela se constrói de maneira paradoxal, já que é pela tentativa de ser o mais "fiel" possível a uma certa "imagem de mundo" - com sua descrição levada às últimas consequências - que o autor acaba por nela introduzir um "elemento revolucionário".

Jorge Luis Borges, no conto "Do rigor na Ciência”, também constrói sua narrativa no sentido de afirmar e descrever exaustivamente o mundo, a ponto de chegar a uma imagem paradoxal de substituição e destruição do mesmo:

Naquele Império, a Arte da Cartografia atingiu uma tal perfeição que o mapa duma só Província ocupava toda uma Cidade, e o mapa do Império, toda uma Província. Com o tempo, esses Mapas Desmedidos não satisfizeram e os Colégios de Cartógrafos levantaram um Mapa do Império que tinha o tamanho do Império e coincidia ponto por ponto com ele. Menos Apegadas ao Estudo da Cartografia, as Geraçóes Seguintes entenderam que esse extenso Mapa era Inútil e não sem Impiedade o entregaram às inclemências do Sol e dos Invernos. Nos Desertos do Oeste subsistem despedaçadas Ruínas do Mapa, habitadas por Animais e por Mendigos. Em todo o País não resta outra relíquia das disciplinas geográficas ${ }^{19}$.

18 LOTMAN, Iuri. A estrutura do texto artístico. Lisboa: Estampa, 1978, p. 386.

19 BORGES, Jorge Luis. Obras Completas I. São Paulo: Globo, 1999, p. 311. 
Como no conto de Borges, os inumeráveis exercícios de descriçâo conduzem no mais das vezes a uma espécie de malogro, pois resultam quase sempre impossíveis de serem levados efetivamente a cabo. Entretanto, ainda que tendentes ao fracasso - e talvez exatamente por isso -, esses exercícios precipitam a emergência da problematização do estabelecimento e da disposição de fronteiras fixas para os espaços e objetos a serem descritos. As séries descritivas levam ao questionamento da sensação de obviedade e evidência que cerca nossa experiência com o espaço, sublinhando com isso o caráter imaginário da mesma. Por isso, escreve Perec sobre a utilização de objetos e situaçóes cotidianas e a necessidade de não fechar os olhos para essas novas possibilidades ficcionais: "Simulacros de espaço, simples pretexto à nomenclatura: mas não é necessário fechar os olhos para que este espaço suscitado pelas palavras, este espaço mesmo do dicionário, este espaço mesmo do papel, se anime, seja povoado, seja preenchido." ${ }^{20}$ Perec questiona, discute e expande, assim, os limites e as classificaçóes do campo literário.

\section{Mais espaços e possibilidades}

Ao empreender o que parece ser simples descrição e nomeação dos espaços, Perec coloca em questão as noçóes mais básicas e óbvias relativas à oposição entre discursos ficcionais e referenciais. O objeto da descrição, por vezes, é o próprio espaço do texto, o que força o leitor a uma revisão da própria noção de descrição, uma vez que nestes momentos não há objeto referencial ou extraliterário a ser descrito: o que se descreve é o espaço mesmo onde a descrição está acontecendo. Perec preenche, assim, o espaço Página de quase todas as formas possíveis. Muitas vezes, de modo lúdico; em outras, atribuindo à escrita funçốes simples, porém nunca antes pensadas. Ele escreve para se percorrer, e percorre-se horizontalmente, faz citaçóes, escreve à margem da folha. Apresenta o tamanho médio de uma folha de papel, pensa em quantos hectares seriam necessários para imprimir as obras de Alexandre Dumas. Afirma que em qualquer folha é possível narrar pequenos

20 “Simulacre d'espace, simple prétexte à nomenclature: mais il n’est pas nécessaire de fermer les yeux pour que cet espace suscité par les mots, ce seul espace de dictionnaire, ce seul espace de papier, s'anime, se peuple, se remplisse." PEREC, Georges. Espèces d'espaces. Paris: Galilée, 2000, p. 27. 
acontecimentos: um encontro, o preenchimento de um cheque, uma carta administrativa. Faz-se um jogo de palavras, jogos de letras que são chamados, de forma comum, ideias. É possível, ainda nesse pequeno espaço, ler o humor, a hora, a precisão de determinada pessoa na execução de atividades ordinárias. Uma infinidade de elementos, situações, narrações, coisas cotidianas e inesperadas. A infinidade de representaçóes na Página é atribuída às inúmeras possibilidades do alfabeto. Pode-se escrever à margem, de cima para baixo, em diagonal. Assim aparecem as primeiras imagens de simetria que serão trabalhadas por Perec de forma exaustiva. O autor inicia Espèces d'espaces fazendo referência à diagonal:

J'écris: je trace des mots sur une page. Lettre à lettres, un texte se forme, s'affirme, s'affermit, se fixe, se fige: une ligne assez strictement

$$
\begin{aligned}
& \mathrm{h} \\
& \mathrm{o} \\
& \mathrm{r} \\
& \mathrm{i} \\
& \mathrm{z} \\
& \mathrm{o} \\
& \mathrm{n}
\end{aligned}
$$

e

se dépose sur la feuille blanche ${ }^{21}$.

Em seguida, Perec discute a possibilidade de escrever em diversas folhas e em diversas situaçôes. De escrever, reescrever, copiar, apagar, ficcionalizar, romantizar, tudo num espaço único, num aleph. Como no capítulo dedicado ao espaço da página ${ }^{22}$ :

21 PEREC, Georges. Espèces d'espaces. Paris: Galilée, 2000, p. 18.

22 PEREC, Georges. Espèces d'espaces. Paris: Galilée, 2000, p.22. 


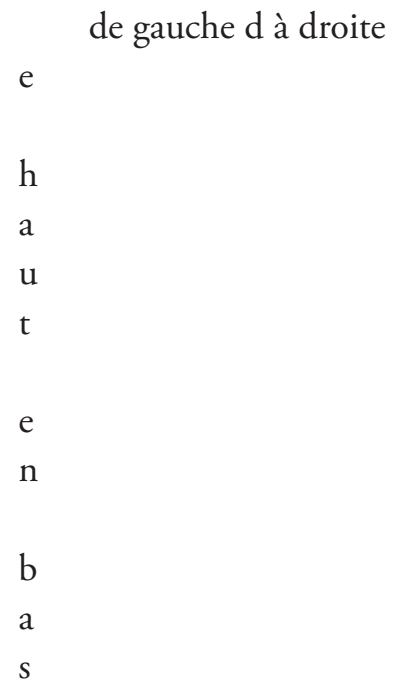

Nesse mesmo capítulo, Perec faz a primeira referência a $O$ Aleph, de Borges, e suas inúmeras possibilidades ficcionais: "L’aleph, ce lieu borgésien ou le monde entier est simultanément visible, est-il autre chose qu'un alphabet?"23. A página passa a ser, então, o próprio espaço do texto; e o alfabeto, seu universo, o seu Aleph.

Em relação às referências (diretas ou escondidas), à teoria do romance, à literatura sob restrições (contraintes) e ao hibridismo literário, Perec escreve $A$ vida modo de usar, que tem como subtítulo Romances. O livro tem também o intuito de discutir os aspectos teóricos de uma obra ficcional. Assim escreve Claude Burgelin:

Construir a torre de Babel, escrever um romance que contenha todos os tipos de romances; colocar em cena dezenas de vidas simultaneamente; evocar modos de usar da existência tão diversa quanto possível; deixar seguir múltiplos tempos a partir desse espaço fechado; obrigar a evocaçãodemilharesdeobjetos, emblemas, imagensedarvidaaesse propósito; juntar o prazer da infância (jogos, encaixes, listas, quebra-cabeças, livrosdeaventuras, trocadilhos, adivinhas, cadeias

23 PEREC, Georges. Espèces d'espaces. Paris: Galilée, 2000, p. 26. 
ao infinito) e combinatórias mais sofisticados; abolir, subverter, ultrapassar fronteiras entre texto e imagem, narrativa e ícones, transformaraliteraturaemumacópiaminiaturizadadomundoeda literatura;aprenderaolharelererrandosemparar;metamorfosearo enciclopedismo em material romanesco; estruturar claramente um romancelabiríntico, tornar móvel um romance-imóvel, dirigir um romance-jogo de xadrez (em todos os sentidos da palavra). Estas são algumas das proezas do acrobata $\operatorname{Perec}^{24}$.

Os procedimentos descritivos com frequência aparecem associados a discursos referenciais e miméticos. Mas é interessante notar que o tipo de mimese realizada por Perec é distinto daquele cujo sentido é comumente atribuído a essa noção. Vemos aí algo que poderíamos chamar de uma mimese prospectiva, em vez de uma mimese retrospectiva: prospectiva no sentido de que não há primazia ontológica do objeto, do referencial a ser descrito, sobre a descrição. A descrição é simultânea ao objeto, ao referente; ou mesmo, em algumas situações, é apenas através da descrição que o referente passa a existir. Esse tipo de descrição performativa presente em Espèces d'espaces lembra a injunção apontada por Michel Foucault em $O$ pensamento do exterior ${ }^{25}$ como fundadora do discurso literário: "eu falo", que pode ser desdobrada em "eu falo que falo". De modo análogo, a mimese prospectiva de Perec poderia ser resumida no enunciado "eu estou descrevendo que descrevo".

24 Construire la tour de Babel, écrire un roman qui contiendrai toutes sortes de romans; mettre en scène des dizaines de vies en même temps; évoquer des modes d'emploi de l'existence aussi divers que possible; laisser filer des temps multiples à partir de cet espace clos; imposer l'évocation de milliers d'objets, d'emblèmes, d'images et donner vie à ce proposent; faire le joint entre les plaisirs de l'enfance (jeux, emboîtements, listes, puzzles, livres d'aventures, calembours, devinettes, enchaînements à l'infini) et les combinatoires les plus sophistiquées; abolir, subvertir, déplacer les frontières entre texte et image, narratif et iconique; transformer la littérature en un copiage-miniaturisation du monde et de la littérature; apprendre à regarder et lire en trompant sans cesse l'œil; métamorphoser l'encyclopédisme en matériau romanesque; charpenter clairement un roman-labyrinthe, rendre mobile un roman-immeuble; mener son terme un roman-jeu d'échecs (dans tous les sens de ceux deux mots). Telles sont quelques-unes des prouesses de Perec l'acrobate BURGELIN, Claude. Georges Perec. Paris: Éditions Seuil, 1988, p. 177.

25 FOUCAULT, Michel. O pensamento do exterior. São Paulo: Princípio, 1990. 


\section{Descrição e ilusão referencial}

Após as considerações desenvolvidas sobre o estatuto da descrição em $E s$ pèces d'espaces, parece-nos que, ao classificar o livro de Perec como não ficção, Sturrock foi vítima da armadilha daquilo que Barthes chamou a "ilusão referencial". Vamos procurar apontar algumas relaçóes entre os textos descritivos e a noçấo de ilusão referencial, explicitada por Barthes em vários momentos de seu trabalho de análise estrutural da narrativa, em especial no artigo "O efeito de real" ${ }^{26}$.

A análise estrutural tem por objetivo identificar a função e o papel dos diversos elementos do tecido narrativo. Barthes procurou isolar alguns deles - de modo geral, os que forneciam as grandes articulaçóes, os pontos de mudança, os shifters -,e se deparou com alguns campos de exclusão, pormenores inúteis e supérfluos com relação à estrutura. Esses pormenores inúteis são, invariavelmente, trechos de descrição, aos quais Barthes se refere como "luxo da narraçáo", uma vez que não fariam avançar em nada a informação narrativa. Apesar de seu caráter inútil, Barthes reconhece nesses pormenores um fator inquietante e enigmático:

[...] assim fica sublinhado o caráter enigmático de qualquer descrição, a respeito da qual é preciso dizer uma palavra. A estrutura geral da narrativa, aquela, pelo menos, que até agora tem sido analisada aqui e ali, aparece como essencialmente preditiva; esquematizando ao extremo, e sem levar em conta os numerosos desvios, atrasos, reviravoltas e decepçóes que a narrativa impóe institucionalmente a esse esquema. [...] Bem diferente é a descrição: não tem qualquer marca preditiva; "analógica”, sua estrutura é puramente somatória e não contém esse trajeto de escolhas e alternativas que dá à narração um desenho de vasto dispatching, dotado de uma temporalidade referencial (e não mais apenas discursivas). [...] A descrição aparece assim como uma espécie de "próprio" das linguagens

26 BARTHES, Roland. "O efeito de real”. In: BARTHES, Roland. O rumor da língua. São Paulo: Martins Fontes, 2004, p. 75-82. 
ditas superiores, na medida, aparentemente paradoxal, em que ela não se justifica por nenhuma finalidade de ação e comunicação. A singularidade da descrição (ou do pormenor inútil) no tecido narrativo, a sua solidão, designa uma questão de maior importância para a análise estrutural das narrativas. É a seguinte questão: tudo, na narrativa, seria significante, e senão, se subsistem no sintagma narrativo alguns intervalos insignificantes, qual é, definitivamente, se assim se pode dizer a sua significância? ${ }^{27}$

A descrição figura para Barthes, assim, como um tipo de estrutura paratáxica, ou seja, na qual em lugar de uma hierarquia de elementos tem-se apenas uma somatória dos mesmos. Enquanto para Lotman a hierarquia entre os elementos presentes num texto é vital para a caracterização da trama, para Barthes este tipo de linguagem não hierarquizada, na qual a descrição está contida, é uma "linguagem superior".

Ainda segundo Barthes, a descrição nem sempre foi subordinada ao realismo tal como na literatura moderna, e certa tradiçấo da descrição sobreviveu desde a Idade Média, na qual "não havia nenhum acanhamento em colocar leóes e oliveiras numa região nórdica; a verossimilhança aqui não é referencial, mas abertamente discursiva: são as regras genéricas do discurso que fazem a lei" ${ }^{28}$.

Nesse mesmo sentido da verossimilhança discursiva, parece avançar Perec em certos momentos de Espèces:

Nous vivons dans l'espace, e dans ces espaces, dans ces villes, dans ces campagnes, dans ces couloirs, dans ces jardins. Cela nous semble évident. Peut-être cela devrait-il être effectivement évident Mais cela n'est pas évident, cela ne va pas de soi. C'est réel, évidemment, et par conséquence, c'est vraisemblablement rationnel. On peut toucher. On peut même se laisser aller à rêver. Rien, par exemple, ne nous empêche de concevoir des choses qui ne seront ni des villes ni des campagnes (ni de

27 BARTHES, Roland. O rumor da língua. São Paulo: Martins Fontes, 2004, p. 183. 
banlieues), ou bien des couloirs de métropolitain qui seraient en même temps des jardins. Rien ne nous interdit non plus d'imaginer un métro en pleine campagne $[\ldots]^{29}$.

A evidência do espaço é contestada. Apesar do caráter real e verossimilhante das descrições dos espaços que habitamos, as leis do discurso não impedem que imaginemos outras disposiçóes espaciais. Vemos aqui, portanto, um deslocamento discreto da preocupação com a disposiçáo dos objetos e do espaço em direção a um questionamento dos limites da linguagem.

Curiosamente, assim como Barthes nota o "efeito de real" em certos elementos sem função do ponto de vista da estrutura narrativa, é com a tentativa de descrição de um espaço inútil que Perec alcança uma conclusão-chave para a compreensáo de todo o experimento com a linguagem empreendido em $E s$ pèces d'espaces: "Il m’a été impossible, en dépit des mes efforts, de suivre cette pensée, cette image, jusqu'au bout. Le langage lui-même, me semble-t-il, s'est avéré inapte à décrire ce rien, ce vide, comme si l'on pouvait parler que de ce qui est plein, utile et fonctionnel" 30 .

Apesar de a existência empírica de tal espaço inútil ser perfeitamente possível e até verossimilhante, do ponto de vista discursivo Perec encontra grande dificuldade em imaginar e descrever o nada, aquilo que não tem funçấo. Para descrever o não funcional, esbarra-se em algumas limitações da linguagem, que parece apenas constituída de modo a poder falar do pleno, do útil, do funcional.

No espaço apresentado por Perec como "apartamento", são descritos pequenos e cotidianos acontecimentos: sua convivência com uma velha vizinha, o modelo caricatural de uma família em sua relação rotineira com os cômodos, móveis que estão dispostos em determinados quartos e as ocorrências que giram em torno dessas configuraçóes. Perec sugere um apartamento diferente do que os arquitetos e urbanistas propóem, um espaço não mais relativo às atividades cotidianas, mas resultante de funçôes de relaçóes, funções sensoriais. Um apartamento formado por sete quartos, cada um a ser utilizado num dia da semana. Existem cômodos utilizados em sábados e domingos em abun-

29 PEREC, Georges. Espèces d'espaces. Paris: Galilée, 2000, p. 14.

30 PEREC, Georges. Espèces d'espaces. Paris: Galilée, 2000, p. 66. 
dância, como a "segunda" casa ou a "casa de fim de semana". Também não seria menos inútil conceber um cômodo exclusivo para segunda-feira do que construir vilas que só serão utilizadas sessenta dias ao ano.

Perec tenta conceber também um espaço totalmente inútil, deliberadamente inútil, sem função nenhuma. Argumenta as impossibilidades de linguagem para tanto, já que o ato de descrever impede a descrição do nada, do vazio. Pensa em habitar um apartamento imenso, tão grande que seria impossível saber quantos cômodos nele existem. Onde todos os cômodos têm uma função específica, exceto um. Esse cômodo seria a chave para todos. Não seria necessária a existência dos outros, somente desse.

Ao acompanharmos o deslocamento efetuado por Perec - dos objetos a serem descritos para as leis do discurso que tornam possíveis as descrições - e o cotejarmos juntamente com as questóes ligadas à funcionalidade da linguagem, vislumbramos o que Barthes chamou de "ilusão referencial" e as formas como ela se aproxima das linguagens descritivas, através da ilusão mesma de que uma notação é inútil ou insignificante do ponto de vista da estrutura da narrativa. Ao tentar empreender uma descrição pura, como nos vários exercícios de empreendidos por Perec, somos levados a acreditar que um objeto pode ser denotado por uma única palavra, quando na verdade a palavra pura não existe - os itens do apartamento que Perec relaciona não existem em si mesmos, mas apenas quando situados num sintagma ao mesmo tempo referencial e sintático. No momento mesmo em que se julga denotarem tais detalhes diretamente o real, nada mais se faz, de maneira escamoteada, do que significá-los. É a categoria do real (e não os seus conteúdos contingentes) que é significada; noutras palavras, "produz-se um efeito de real, fundamento dessa verossimilhança inconfessa que forma a estética de praticamente todas as obras correntes da modernidade" 31 .

A aparente ausência de sentido e função do objeto descrito no conjunto do tecido narrativo, como se ele fosse citado apenas para referir-se a certa concretude, é o truque retórico que funda o "efeito de real". Dessa forma, o exercício descritivo de Perec institui um questionamento a respeito do estatuto da ficcionalidade e da representação, assim como o faz uma parte da literatura e da arte contemporânea dedicadas à serialização: os inventários, os conjuntos,

31 BARTHES, Roland. O rumor da lingua. São Paulo: Martins Fontes, 2004, p. 190. 
as séries fragmentárias, as colagens. No romance $A$ vida modo de usar ${ }^{32}$, Perec faz um inventário exaustivo de todos os habitantes do prédio: "Um inventário que - pelo excesso de ordenação e detalhamento - acaba também por perder sua própria eficácia enquanto procedimento taxonômico diante da proliferação excessiva dos objetos e detalhes que se acumulam enquanto 'materiais da vida' dos personagens" 33 .

Já no livro Pensar/Classificar, Perec se dedica a uma teorização não convencional da classificação, mostrando sua fixação por listas, glossários, índices e várias modalidades de ordenação do mundo: "Lamentablemente no funciona, nunca funcionó, nunca funcionará. Lo cual no impedirá que durante mucho tiempo sigamos clasificando los animales por su número impar de dedos o por sus cuernos huecos" 34 .

Talvez todas essas expressóes provoquem uma contestação do valor referencial, introduzindo a dimensão necessariamente ficcional de qualquer discurso, em oposição ao saber tático que considera, de maneira inversa, o ficcional como um subtipo discursivo. Talvez o que tenha escapado a Sturrock seja justamente a sutileza ficcional de Espéces d'espaces, discreta como uma pequena seta em um mapa. $\mathrm{O}$ foco de interesse incide aí não na questão da exatidão ou da coerência dos critérios classificatórios utilizados por John Sturrock ao definir Espèces como uma não ficção, e sim na surpresa que essa forma de classificar proporciona. E, com essa surpresa, na constatação das possibilidades de problematização que a obra de Perec oferece sobre o próprio estatuto do ficcional.

\title{
LANGUAGE, LITERATURE AND THEORY IN GEORGES PEREC
}

\begin{abstract}
This article approaches some possible relations between space and literature within the work of the French writer Georges Perec. The book Espèces d'espaces, published in
\end{abstract}

\footnotetext{
32 PEREC, Georges. A vida modo de usar. São Paulo: Companhia das Letras, 1989.

33 MACIEL, Maria Esther. A memória das coisas. Rio de Janeiro: Lamparina, 2004, p. 15.

34 PEREC, Georges. Pensar/Classificar. 2. ed. Barcelona: Gedisa, 2001, p. 111.
} 
1974, is taken as a major reference for a reflection about how its narrative structure produces displacements in its fictional status.

KEYWORDS: space; fiction; Georges Perec; classification.

Recebido em: 19/06/2012

Aprovado em: 17/01/2013 